\title{
La ilusión del Uno. La infancia como "espacio libre" y el humor como vehículo a lo trascendente en la narrativa de Mario Levrero*
}

Fecha de recepción: 20 de mayo de 2021

Fecha de aprobación: 15 de julio de 2021

\section{Resumen}

Proponemos analizar el papel que cumple el humor en la obra del escritoruruguayo Mario Levrero. A partir de la lectura crítica de relatos de distintos momentos de su trayectoria, destacamos que se trata de un recurso indispensable para la construcción de su poética que le permite delimitarse de los presupuestos estéticos de lo que Ángel Rama denomina "la generación crítica" (19). El uruguayo concibe su escritura como un dispositivo terapéutico y al humor como un vehículo hacia lo trascendente. Desde una cosmovisión que se apropia de restos del romanticismo, la parapsicología y el psicoanálisis junguiano, persigue en sus textos el acceso al Espíritu/Inconsciente, un camino (im)posible al (auto) conocimiento. La literatura se convierte en un "espacio libre" que asocia a la infancia, se realiza en la escritura y se contrapone a la vida alienada de los adultos, en particular, de la del yo cotidiano del autor, Jorge Varlotta.

Palabras clave: Mario Levrero; Literatura Latinoamericana; humor; infancia; escritura.

Citar: Rivadeneira, Blas. "La ilusión del Uno. La infancia como "espacio libre" y el humor como vehículo a lo trascendente en la narrativa de Mario Levrero". La Palabra, núm. 41, 2021, e12866. https://doi. org/10.19053/01218530.n41.2021.12866

\section{Blas Gabriel Rivadeneira}

Consejo Nacional de Investigaciones Científicas y Técnicas. Universidad Nacional de Tucumán. Doctor en Letras. Becario posdoctoral del Consejo Nacional de Investigaciones Científicas y Técnicas (CONICET) de Argentina. blas.rivadeneira@filo.unt.edu.ar iDhttps://orcid.org/0000-00032452-1049

* Artículo de reflexión.

El artículo deriva de la investigación sobre la poética del escritor uruguayo Mario Levrero realizada para la tesis doctoral del autor, financiada por el Consejo Nacional de Investigaciones Científicas y Técnicas (CONICET) de Argentina, y se enmarca dentro del proyecto PIUNT "Teatralidades de la memoria". 


\title{
The illusion of the One. Childhood as "free space" and humor as a vehicle for the transcendent in Mario Levrero's narrative
}

\begin{abstract}
We propose to analyze the role that humor plays in the work of the Uruguayan writer Mario Levrero. From the critical reading of stories from different moments of his career, we highlight that it is an indispensable resource for the construction of his poetic that allows him to delimit himself from the aesthetic presuppositions of what Ángel Rama (19) calls the critical generation. The Uruguayan conceives his writing as a therapeutic device and humor as a vehicle towards the transcendent. From a worldview that appropriates remains of romanticism, parapsychology and Jungian psychoanalysis, Levrero pursues in his texts access to the Spirit/Unconscious, an (im)possible path to the (self)knowledge. Literature then becomes a "free space" that associates with childhood, is realized in writing and is opposed to the alienated life of adults, in particular, that of the everyday self of the author, Jorge Varlotta.
\end{abstract}

Keywords: Mario Levrero; Latin American Literature; humor; childhood; writing. 


\section{A ilusão do Um. A infância como "espaço livre" e o humor como veículo ao transcendente na narrativa de Mario Levrero}

\section{Resumo}

Propomos analisar o papel que cumpre o humor na obra do escritor uruguaio Mario Levrero. A partir da leitura crítica de relatos de distintos momentos de sua trajetória, sublinhamos que se trata de um recurso indispensável para a construção da sua poética, que lhe permite delimitar-se aos orçamentos estéticos, denominados por Ángel Rama como "a geração crítica" (19). O uruguaio concebe a sua escrita como um dispositivo terapêutico e ao humor como um veículo para o transcendente. De uma cosmovisão que se apropria de restos do romantismo, a parapsicologia e a psicanálise junguiana, procura em seus textos o acesso ao Espírito/ Inconsciente, um caminho (im)possível ao (auto)conhecimento. A literatura se torna em um "espaço livre" que associa-se à infância, realiza-se na escrita e contrapõe-se à vida alienada dos adultos, em particular, a do eu cotidiano do autor, Jorge Varlotta.

Palabras clave: Mario Levrero; Literatura Latinoamericana; humor; infância; escritura 


\section{Introducción. La verdad del nombre falso}

El humor, en particular el trabajo con el absurdo, es una de las características más reconocibles del proyecto escriturario de Mario Levrero. Se trata de una matriz creativa que abarca gran parte de su obra y llega a excederla en esa zona de borde, en el que su fantasma autoral se cruza con figuras que componen otras dimensiones de su producción: el uruguayo, en paralelo a su trayectoria literaria, publica con la firma de Jorge Varlotta - $\mathrm{u}$ otros heterónimos- las historietas El santo varón, El llanero solitario y Los profesionales, textos para revistas como Misia Dura y realiza colaboraciones con el músico Leo Maslíah que tienen también esta faceta humorística. Desde los universos oníricos en la primera etapa de su producción al hiperrealismo de los diarios en la última, el humor es una sutura que amalgama distintos géneros, firmas y modos escribir.

Jorge Mario Varlotta Levrero nace en Montevideo en 1940. Mario Levrero es una de las tantas máscaras de las que supo valerse para configurarse e irrumpe varios años después, en 1966, como el heterónimo que elige para presentarse en sus textos "más literarios". El uruguayo explica la adopción del nombre a partir de una necesidad doble: en primer lugar, porque señala una distancia entre el autor, como efecto de la propia práctica de escritura, y su yo cotidiano alienado, Jorge Varlotta; en segundo lugar, le permite separar su producción literaria de sus numerosos textos de índole puramente humorística debido a la mirada inquisitiva de un campo hegemonizado, por lo que Ángel Rama denomina "la generación crítica" (19). Afirma Levrero al respecto: "La generación anterior a la nuestra en Uruguay —explica— se denomina la 'generación crítica'; para mí fue una propuesta totalmente estéril que nada aportó como movimiento, apenas unas cosas aisladas. Dejó formas hipercríticas, hiperintelectuales y con gran nivel de exigencia" (Gandolfo 29).

En esa arte poética que es la "Entrevista imaginaria con Mario Levrero por Mario Levrero" el uruguayo destaca que la crítica ejerce una "función represora, de tipo policial [...]" $(E l$ portero 180) por lo que su papel es impedir que "la locura" de los textos se expanda al resto del cuerpo social. Tal es la presión que siente al respecto, en sus comienzos como escritor, que la primera edición de 1975 de la novela policial paródica Nick Carter se divierte mientras el lector es asesinado y yo agonizo aparece firmada por Jorge Varlotta, ya que la considera liviana para la exigencia de la literatura, con mayúscula, que pregona la generación precedente. En las ediciones posteriores el libro ya se publica con la firma de Levrero. En clave de ajuste de cuentas no faltan oportunidades donde el rioplatense fustigue a la llamada generación crítica y a Rama, en particular, por el supuesto "libertinaje de la imaginación" (Rama 244) que este le marca luego de la lectura de sus primeros libros, La ciudad y La máquina de pensar en Gladys. De hecho, el uso del humor como parte de una defensa de este exceso, se convierte en uno de los pilares para delimitar su propuesta estética respecto a los postulados de los autores anteriores. A su vez, esta ruptura con las tendencias mayoritarias del campo uruguayo de la época, lleva a que Rama (222-223) lo vincule con la genealogía de los raros.

El nombre falso, Mario Levrero, da cuenta, entonces, de un desplazamiento y de un enmascaramiento. Martín Kohan resalta, a propósito del cambio de nombre por parte de los militantes revolucionarios, el espesor de un gesto que, a la vez, implica la impugnación de 
la legalidad constituida y es garantía de autenticidad política. Kohan plantea que, "dialéctica de la documentación personal: la falsificación del pasaporte falso señala una verdad política. Y dialéctica de los nombres y los seudónimos: la falsificación del nombre falso se asienta como verdad revolucionaria" (51-2). De manera similar, la intervención del nombre por el uruguayo manifiesta la autenticidad de su poética. La partición de la firma expone la sutura constitutiva de su fantasma de autor, Mario Levrero, efecto de la escritura y del yo cotidiano alienado, Jorge Varlotta, condición de posibilidad para la irrupción del primero. El nombre falso resulta así el verdadero. A propósito, Levrero ironiza: “[ ...] mi cédula de identidad es el trabajo de un hábil falsificador. Mi verdadero nombre es Zbinieg Xjrschtshlavsk; [...] Alvar Tot, Mario Levrero y algún otro que se me perdió, son seres reales: unos enanos [...] a los que hago trabajar para mí" (Rocca 109).

Esta ruptura generacional se manifiesta también en el hecho de que sus primeros relatos aparecen en la revista Los huevos del Plata. El nombre de la publicación - cuyas iniciales son HDP - es una parodia de los títulos serios de una sola palabra que utiliza la camada anterior de escritores, siendo el más emblemático Marcha. Además de contribuir a este gesto diferenciador, propio de la dinámica del campo, en Levrero, el uso del humor adquiere el espesor de una polémica sobre los alcances de la noción de realidad y es clave para el análisis de su poética. Para el rioplatense la escritura, de manera recursiva, es el medio para el acceso y, a la vez, el espacio de realización de un conocimiento que se erige más allá de los límites impuestos por la normativa social. En este sentido, el humor es una forma de producir una sutura de lo que se presenta fragmentado. Esta operación permite superar los aparentes binarismos y tomar contacto con la verdad que, en su cosmovisión, tiene alcances trascendentes y se construye a modo de la ilusión del Uno.

En este trabajo, proponemos abordar el papel del humor en la narrativa de Mario Levrero como elemento constitutivo de su poética. Debido al gran número de relatos con preminencia de lo absurdo y lo humorístico, nos detendremos en diferentes textos de su primera etapa de producción, momento primigenio en el cual decide darle esta modulación distintiva a su obra, y en algunas de sus Irrupciones que integran el núcleo final de la misma, en las que continúa recurriendo a esta matriz que, con matices, perdura a lo largo de toda su trayectoria literaria. Sostenemos, a modo de hipótesis de lectura, que el uruguayo, mediante procedimientos narrativos como el absurdo, la paradoja, la disonancia cognitiva y la parodia, quiebra con los postulados estéticos de la generación crítica y su cosmovisión acotada de lo real. Para Levrero la escritura es un dispositivo terapéutico o mancia que permite la afloración del Inconsciente y el contacto con el Espíritu, como expresión del (auto)conocimiento. Esta aproximación a lo trascendente se configura a modo de un "espacio libre" que se vincula con el imaginario de la infancia.

\section{Levrero y el humor. Breve revisión crítica}

Existen diferentes aportes críticos sobre la presencia del humor en la obra de Levrero. En su lectura fundacional de los primeros libros del uruguayo, Rama (241) resalta que, el por entonces joven autor manifiesta, junto a otras escritoras contemporáneas a las que lo emparenta - Teresa Porzecanski y Cristina Peri Rossi-, un rechazo a la herencia de la generación 
crítica. Esta ruptura se sintetiza en la imagen repetida de la casa en ruinas y la experiencia de inseguridad y variación de la realidad en sus relatos. Como destaca Jesús Montoya Juárez (63), se trata de una lectura que oscila entre la fascinación y la crítica. Rama señala que Levrero construye su prosa a partir de una acumulación heteróclita de imágenes que lo asocian a Kafka y al surrealismo, pero que en el uruguayo "puede no tener fin, que estrictamente no lo tiene salvo la voluntad caprichosa del autor" (243). Si bien el abordaje de conjunto del artículo es elogioso, el crítico ataca este exceso como libertinaje imaginativo. Levrero, no sin alguna vacilación, asume el cuestionamiento como un punto para reafirmar su poética: desde ese plus, en el que cumple un rol fundamental el humor, delimita su proyecto escriturario.

Lecturas posteriores desarrollan algunas de estas aristas planteadas por Rama e iluminan otras. Pablo Fuentes postula el uso del humor como una de las constantes de su narrativa y destaca que, asume la forma del humor negro cuando "irrumpe lo irrisorio en situaciones límites y patéticas" (37). Fuentes vincula el efecto absurdo que quiebra la linealidad mediante la emergencia de lo insólito en los relatos del uruguayo con los gag del cine mudo, en especial de Buster Keaton, en tanto que asocia la rebeldía de los objetos cotidianos y los cambios de roles recurrentes con mecanismos del surrealismo. Hugo Verani (55-7), por su parte, entiende los procedimientos compositivos de Levrero que tienden a la acumulación combinatoria, el vaciamiento de sentido o la reescritura paródica de la historia como una prosa posmoderna que abre puertas al extrañamiento de lo real, detrás de los simulacros. Luciana Martínez (187-88) inscribe a la poética del autor rioplatense en el mapa de filiaciones del Romanticismo y sostiene que, el uso del humor en su obra se relaciona con el anhelo de una forma de conocimiento que reúna ciencia y estética.

En su análisis de La novela luminosa, Matías Núñez (269-72) considera al humor como una estrategia pragmática para decir lo indecible, lo íntimo, lo doloroso o la experiencia luminosa, a la vez, que le permite a Levrero matizar la verdad que enuncia, dejando en la lectura, que, en sus términos, es equiparable a un encuentro sexual o de almas, la tarea de completar ese vacío con la risa. Ramiro Sanchiz (29-31) resalta la distinción entre el humor y el chiste que realiza el uruguayo, cuando señala que el primero no está ligado necesariamente a la risa y es el recurso que se encuentra en los textos literarios. El crítico vincula los planteos biasociativos de Arthur Koestler, que menciona Levrero con la teoría de Peter Marteinson, cuando entiende al humor como resultado de una “'dificultad ontológica' en la que el sujeto percibe que ciertas categorías cognitivas no le permiten comprender la realidad en la que está inmerso. Esa sensación de irrealidad, entonces, despertaría la risa" (31). La recurrencia a esta disonancia cognitiva, concluye Sanchiz (31), es la razón por la que se puede afirmar que su obra es profusa y tiene en el humor uno de sus pilares.

\section{La illusión del uno. El humor como matriz de la poética levreriana}

Para el uruguayo el humor habilita una grieta de acceso a una comprensión más amplia de la realidad, a la superación de las falsas dicotomías como blanco-negro, femenino-masculino que dominan la percepción de los sujetos en el marco de una sociedad que reprime los intentos de ir más allá de esos binarismos. Levrero declara en una entrevista: "La función del humor es permitir la coexistencia de opuestos. [...] permite hacer una síntesis de dos cosas 
contradictorias, que fuera del humor no estarían permitidas. E1 humor te hace expresar la verdad de las cosas" (Gandolfo 87-8). Esta idea de verdad como la ilusión del Uno configura al humor en un vehículo hacia lo trascendente en su cosmovisión de la escritura a modo de una búsqueda del (auto)conocimiento o del Espíritu/Inconsciente. Asimismo, le posibilita delimitarse de los presupuestos estéticos de la generación crítica, al considerar que se sustentan en una concepción limitada de lo real.

Tomás Várnagy menciona tres teorías del humor tradicionales:

La de la superioridad (hostilidad, agresión o menosprecio), que encontramos en Platón, Aristóteles y Hobbes; la de la incongruencia (la risa como respuesta a algo fuera de lugar, ambivalencia, contraste o disociación) en Kant; y la descarga (alivio, sublimación o liberación de la tensión nerviosa) en Spencer y Freud; Bajtín de alguna manera combina las tres. (65)

Si bien es claro que la irrupción de lo insólito, el desplazamiento semántico o la disonancia cognitiva emparentan los procedimientos narrativos de Levrero a la teoría que se sustenta en la incongruencia, los límites no son rígidos y en su obra podemos encontrar superpuestos elementos correspondientes a las diferentes concepciones. A su vez, ciertos mecanismos y posiciones programáticas lo emparentan al surrealismo y a las prácticas desacralizadoras estudiadas por Mijaíl Bajtín en relación con la parodia. En este marco, leemos al humor en modo de eje articulador de su poética a partir de dos núcleos de sentido: su condición de vehículo hacia lo trascendente y su vinculación con la idea de infancia como espacio libre.

Martínez refiere al humor como una estrategia escrituraria de Levrero en su búsqueda, a través de la indagación en su interioridad, de un mayor conocimiento de lo real. Asimismo, destaca la herencia de los postulados de la mística y el romanticismo alemán en su poética: "El humor como camino epistemológico debe entenderse también en este sentido: lo real se presenta en la construcción imaginativa de la fábula" (188). En el ideal romántico, la fábula más irracional puede conducirnos por una experiencia de realidad.

A esta apropiación de los restos del romanticismo y de la mística, deben agregarse las lecturas que el uruguayo hace de la parapsicología y del psicoanálisis. En este aspecto, la función del humor en su poética, que pretende superar los binarismos impuestos por la normatividad social en procura del (auto)conocimiento o el acceso a una realidad más amplia, es similar a la que Germán García analiza en la escritura de otro "raro" de la literatura rioplatense, Macedonio Fernández: "[...] liberarse del sentido (crear un absurdo absoluto) es retornar por un instante a ese momento donde no había diferencia: ser la risa de la madre" (147). García (145-47) plantea que, la ilusión del Uno se produce en la emoción placentera e inesperada de un absurdo que se realiza. Al desplazar al significante del significado produce una grieta en el mandato contractual del superyó habilitando que lo imposible sea posible. La desestabilización constitutiva de materiales narrativos y discursos, la irrupción de lo insólito o la paradoja que se destacan en los relatos levrerianos adquieren el espesor de esta búsqueda (im)posible mediante la escritura. 
El uruguayo construye su imagen de autor como la de un maestro-médico-sacerdote (Rivadeneira). En contraste con la generación anterior, compone una figura excéntrica que se vale de restos de disciplinas y géneros marginales para dar forma a su poética. Esta se organiza a partir del proyecto (im)posible de alcanzar una experiencia luminosa mediante la escritura entendida como una instancia de trance hipnótico. El humor, y en particular el absurdo, la irrupción de lo insólito en un contexto de normalidad, se convierte en un vehículo hacia lo trascendente, de ahí que, en su cosmovisión, la búsqueda del Inconsciente sea asimilable a la del Espíritu. Una grieta frente a la normatividad social y de la lengua que habilita la emergencia del "espacio libre" de la literatura, donde habita Mario Levrero. Lugar que se realiza en la escritura y que el uruguayo asocia a la infancia en oposición a la vida alienada de los adultos, entre ellos, de su yo cotidiano, Jorge Varlotta.

\section{El humor como vehículo hacia lo trascendente}

En el relato "Ese líquido verde" una muchacha de uniforme y ojos verdes llama a la puerta del narrador; es una vendedora que le pide entrar para ofrecerle una muestra gratis de un producto al que describe como un frasco con un líquido verde. Fascinado por la belleza de la mujer, este permite que pase. Sin embargo, con ella ingresa también un circo completo: "Detrás de ella entra un payaso, que se para de manos en el centro de la pieza, y hay más gente afuera" (La máquina 66). Uno a uno ve pasar equilibristas, un domador, camellos, un león, un elefante, una jirafa y un motorista suicida. El relato termina cuando el protagonista le pide a la vendedora que se vaya, llevándose a su circo, y la mujer le responde: "Esa gente no ha venido conmigo" (La máquina 67). En el cuento encontramos la crítica mordaz a la mercadotecnia y su intromisión en la vida de las personas por lo que contiene elementos de la llamada teoría de la superioridad. Lo humorístico, a la vez, está dado por la presencia "fuera de lugar" o desplazada de los miembros del circo. El planteo freudiano de la sublimación de energía psíquica acumulada a partir de chistes obscenos u hostiles, que exponen pensamientos socialmente poco aceptados, no es tan evidente como en otros textos de Levrero, donde lo obsceno se vuelve casi pornográfico, pero está presente en la crítica a la invasión mercantil de la privacidad mediante una fachada que despierta deseos eróticos - la vendedora - , pero que oculta "un mundo" que perturba la tranquilidad del narrador.

En "El crucificado", en cambio, es ostensible este discurso irreverente con el statu quo de valores morales, ya que en el relato hay una apropiación obscena de símbolos asociados con el cristianismo. El cuento narra la llegada a un lugar innominado del Crucificado, un sujeto con características fenotípicas similares a las de Jesús de Nazaret, aunque es descrito como un pordiosero: "Tenía pocos dientes, era flaco y barbudo, muy sucio, la cara arrugada, de transpiración grasienta, y el pelo enmarañado y largo. Un olor mezcla de halitosis, sudor y orina" (Espacios 48). El narrador destaca que, lo que más llama la atención de su figura es "la posición de los brazos perpetuamente abiertos y rígidos" (48) debido a que tiene las manos clavadas a una madera.

Por medio del uso escatológico de los símbolos del cristianismo, Levrero construye un texto que desacraliza el discurso religioso. La operación escrituraria del uruguayo es doble porque a la vez que desestabiliza con un discurso aséptico, abre la posibilidad de un relato místico 
alternativo, excesivo y erótico. De hecho, en "El crucificado" se reescribe la crucifixión como escena fundante, pero con variantes propias de la concepción levreriana del contacto con lo absoluto a través del humor y el erotismo. El visitante es condenado a una nueva crucifixión porque lo encuentran teniendo relaciones sexuales con Emilia, una adolescente virgen que debía ser "desflorada" (Espacios 49), como todas las chicas del lugar, por Eduardo cuando cumpliera los quince años. Tanto el recién llegado como la joven son trasladados a un cerro mientras los pueblerinos, dirigidos por Eduardo, los apedrean y escupen. En el cuento se ironiza sobre esta posible doble crucifixión: el protagonista no puede cargar la nueva cruz que le pretenden imponer, por lo que Emilia lleva dos en su viacrucis, y a él lo cuelgan aprovechando la que ya tenía. En el final, todos los que observan los sacrificios terminan momificados y el visitante muere. Solo quedan Emilia y el narrador, quien la baja de su cruz. La joven, construida a partir de la figura del ánima junguiana que concentra tanto la imagen de la diosa y la prostituta, la salvación y la tentación, presente como un eterno femenino en gran parte de la obra levreriana, es la que reviste de un halo místico al relato: "Sin querer tuve que manosearla un poco para sacarla de allí; pensé que debería sentirme excitado, pero no era posible, era como si yo no tuviera sexo" (Espacios 52). Emilia espera un hijo que va a nacer en tres días y encomienda al narrador que divulgue lo ocurrido: "Ve por el mundo y cuenta lo que has visto" (53).

Bajtín señala a la parodia como una forma carnavalesca de ejercicio de la crítica ideológica que opera mediante la desestabilización de las jerarquías y la desacreditación de valores establecidos, a través de la imitación de modelos que se relativizan. Así como arremete con el discurso religioso, el uruguayo recurre a la parodia en relación con diferentes prácticas como el psicoanálisis (Nick Carter), la lógica (Ya que estamos) y, sobre todo, la literatura: hace intervenciones al género policial en Nick Carter, La banda del ciempiés o "Confusión de la serie negra", a la ciencia ficción en "Los ratones felices", a la entrevista en su autoentrevista imaginaria o, incluso, al diario íntimo en la trilogía luminosa compuesta por "Diario de un canalla", El discurso vacio y La novela luminosa. La narrativa de Levrero parte de esta voluntad desestabilizante de los numerosos materiales de los que se apropia, un desplazamiento que vuelve constitutivo al efecto humorístico en su poética. Este continuo desfasaje, como en el caso de "El crucificado" donde postula un relato religioso alternativo, no es solo negación, sino que se construye en función de articular a la escritura como una búsqueda (im)posible que, a su vez, se realiza en ese discurrir. Tanto el humor como lo erótico funcionan, entonces, como un vehículo hacia lo trascendente.

El absurdo como "irrupción" de otro real o fisura del sentido es el mecanismo humorístico privilegiado en la poética del uruguayo. Esta idea de dispositivo escriturario es central en la literatura levreriana, e incluso, es abordado en forma figurativa explicitando el artificio: en sus relatos aparecen máquinas, flippers, computadoras y, desde ya, la máquina de escritura/ escribir, la materialidad de la escena de enunciación. En La novela luminosa se insiste en esta escena a modo de una imagen que asedia al autor obsesivamente, pero que nunca viene acompañada por el contenido de lo que se escribe. De manera similar, en El discurso vacío, el protagonista realiza ejercicios caligráficos despreocupándose de lo que narra, solo intentando mejorar su letra para encontrar, por medio de una terapia grafológica, un equilibrio en su subjetividad. La escritura se configura en la máquina fundacional de una narrativa poblada 
de artefactos: un discurrir placentero en su materialidad más allá de lo que se narra y un dispositivo terapéutico que habilita la utopía de la reconstrucción plena del sujeto fragmentado de la escena de enunciación.

En "La calle de los mendigos", la irrupción del absurdo está relacionada a la necesidad de desentrañar una pequeña maquinaria: un encendedor. El narrador se dispone a fumar, lleva un cigarrillo a sus labios, pero el aparato no funciona por lo que inicia un desopilante intento de arreglarlo. Ante cada resorte, tornillo o pieza que extrae, el artefacto parece estar diseñado con una estructura más compleja que se expande hasta llegar a ocupar toda la habitación. El uso del encendedor no tiene importancia, comenzado el relato lo que interesa es el propio mecanismo y no su aplicabilidad. El disparador es dejado de lado y el protagonista se pierde en su propia curiosidad como un niño jugando. Lo mismo ocurre con los flippers, las computadoras y la escritura que resaltan en su obra como improductivas. Las máquinas de Levrero no están en función del trabajo, el gran organizador de la sociedad burguesa, sino que se utilizan para el ocio. El rioplatense se considera un autor amateur que reivindica la literatura a modo de un espacio libre asociado a la infancia y se delimita del profesional que asume la escritura como un trabajo.

En "La máquina de pensar en Gladys" de este artefacto solo se refiere que "estaba enchufada y producía el suave ronroneo habitual" (La máquina 9). En tanto que, en "La máquina de pensar en Gladys (negativo)", el relato original es fisurado por la emergencia de un imaginario desbordante e insólito: "La ventana del baño chico, al fondo, está cerrada, y el caballo degollado continúa pudriéndose en la bañera" (La máquina 119). El aparato, esta vez, no es mencionado en el cuerpo del texto, sino que lo asedia de tal forma que induce a relacionar la secuencia onírica y el derrumbe de la casa como resultados de su presencia fantasmática. La irrupción de ese otro real como negativo del relato homónimo devela los mecanismos de la poética de Levrero: el discurrir escriturario es una máquina que posibilita la afloración del Inconsciente/Espíritu.

Esta concepción poética lo emparenta con el surrealismo. El uruguayo manifiesta reticencias con esta vinculación, ya que, de hecho, el Inconsciente al que se remite no es el freudiano, sino uno que construye valiéndose de sus lecturas de Freud, pero también de disciplinas marginales como la parapsicología y las teorías de Jung. Empero, también son conocidos los desplantes del padre del psicoanálisis para con las elaboraciones surrealistas. Breton y su grupo, como Levrero, hicieron su particular apropiación teórica, su propia lectura, inventando un psicoanálisis que legitime - $-\mathrm{y}$ a la medida de — su propuesta estética. Más allá de las diferencias programático-políticas entre las aspiraciones de producir un cambio radical en la sociedad de parte del surrealismo y el planteo más modesto de Levrero de concebir la literatura como una terapia individual, existen puntos de contacto en la forma de pensar la escritura a modo de un dispositivo capaz de incidir y transformar la subjetividad. Incluso en los medios o técnicas empleadas como lo maravilloso, la belleza compulsiva o el azar objetivo, hay una relación con los procedimientos utilizados por el uruguayo. Esa búsqueda de una "iluminación profana" que señala Walter Benjamin (46) en los surrealistas, o el pensar lo maravilloso como una erupción de las contradicciones de lo real, es asimilable a la poética de Levrero. En este sentido, en una de sus Irrupciones escribe con ironía: "Es mi 
forma de promocionar el surrealismo en un mundo muy apegado al sentido común. Todavía no he llegado a conocer una mayor belleza que la del absurdo" (263).

\section{La infancia como espacio libre}

En la cosmovisión levreriana la búsqueda de ese "espacio libre" a través de la escritura está asociada a la infancia. El mundo adulto, en contraposición, está signado por la acción represiva de las instituciones sobre el sujeto, en primer lugar, sobre el niño con el ingreso a la escuela. Leemos en una de sus Irrupciones: "[...] apreció una bandada de niños con guardapolvo blanco y moña azul; durante el resto del año no volví a verlos, como si hubieran existido solamente para recordarle al mundo que aquel día se terminaba la libertad irrestricta de la infancia" (139). La pérdida de la infancia es construida como el final de una etapa de libertad, propicia para la actividad creadora, que Levrero pretende recuperar a partir de la práctica literaria. La escritura se configura, entonces, no solo como una máquina, sino como un juguete que (re)crea la curiosidad y el impulso de los juegos infantiles: "lo que yo perseguí a través de los juguetes era una mezcla de investigación y de creación mágica —algo que solo pude conseguir años más tarde a través de la literatura y, muchos años más tarde, a través de la computadora" (Irrupciones 421). La epistemología levreriana que conjuga saberes legitimados con marginales, científicos y esotéricos, está presente en la composición de este juguete que es la máquina de escritura.

Situados en la etapa final de su trayectoria literaria, los textos que integran las Irrupciones tienen la particularidad de que, antes de ser reunidos en un libro en 2001, fueron publicados en la revista Postdata. Una escritura marcada por la mayor exposición que implica hacerlo en un medio masivo y cuyo género fluctúa entre la crónica, la ficción y los experimentos autoficcionales de sus relatos-diario. Aunque son evidentes modulaciones propias de la trilogía luminosa, el humor mantiene una presencia relevante. Tanto la serie titulada "Agujero en un buzo celeste" como la agrupada bajo el nombre "Elvis", se componen de un grupo de relatos que dan cuenta de esta tendencia en la poética levreriana por encontrar el detalle insólito y la observación de lo lateral como procedimientos narrativos.

El narrador recorre la ciudad en busca de estas fisuras del paisaje urbano. Un cartel en una vidriera que dice: "UN ZAPATO URUGUAYO CREA UN EMPLEO. UN ZAPATO IMPORTADO CREA UN DESOCUPADO” (Irrupciones 405), es el disparador para un discurrir desopilante construido a partir de lecturas literales del mismo. De manera similar, un comunicado del Sindicato Médico del Uruguay le permite elucubrar posibles sentidos al detenerse en la ambigüedad del enunciado. Se configura, entonces, como un flâneur fóbico que camina rastreando estas desarticulaciones que habilitan una lectura a contrapelo de esa espacialidad reglada por lo utilitario y lo mercantil.

En su trabajo con el imaginario infantil, la máquina de escritura levreriana no abandona su predilección por exponer su propio artificio. En "Las aventuras del ratón Mouse", Levrero recurre a un lenguaje afectado hasta la saturación para narrar la historia de un ratón que "no es, por así decirlo, un verdadero ratón" (Irrupciones 260). Ilustrados toscamente por el 
mismo uruguayo, en la serie de relatos se exhiben las costuras de la representación literaria, mecanismo que aparece subrayado por los trazos infantiles de la figura del ratón que complementa al texto.

Una referencia ineludible al asediar la poética de Levrero y, en particular, sus modos de construir lo maravilloso y el imaginario de la infancia es Lewis Carroll. Caza de conejos es una novela corta en la que es evidente esta herencia, aunque el rioplatense da un paso más allá al permitir la emergencia explícita de lo erótico y la violencia. Escrita en 1973, está compuesta por una serie de microrrelatos que conforman una suerte de totalidad provisoria. El prólogo y el epílogo están escritos con las mismas frases, pero en un orden inverso por lo que la novela comienza y termina con la misma oración: "Fuimos a cazar conejos". El relato es un ejercicio del libertinaje imaginativo al que refiere Rama (244). Como destaca Rómulo Cosse (38-41), Caza de conejos transgrede la denotación mediante la repetición y la variación. Sin embargo, la ruptura programática que formula el libro es más compleja: se construye desde la subversión permanente de los límites y las reglas que el mismo texto va planteando. Los cazadores pueden terminar siendo cazados: "Los cazadores gustan de adornarse, y a menudo el colorido de estos adornos es su perdición: es fácil distinguirlos entre el follaje y tomarlos por sorpresa" ( Caza 27); pueden no ir a cazar conejos: "Dicen que van a cazar conejos, pero se van de picnic" (33); los conejos no siendo conejos: "Decimos que vamos a cazar conejos pero en el bosque no hay conejos. Vamos a cazar muchachas salvajes, de vello sedoso y orejas blancas" (43); la caza no siendo una caza: "De hábitos sedentarios, jamás se nos ocurriría algo así como ir al bosque a cazar conejos. Preferimos criarlos en el castillo" (52); incluso, se llega a poner en duda su existencia: "Si bien entre nosotros casi no se habla de otra cosa que de conejos, en realidad nunca hemos visto uno. Dudamos incluso de su existencia. En nuestras conversaciones el conejo oficia de metáfora, o de símbolo" (53).

El relato desafía los límites genéricos y de sentido mediante la recurrencia a imágenes absurdas que juegan con las expectativas del lector. El humor es constitutivo del texto y se produce a partir de estos desplazamientos: "No llevamos a nuestros niños a las cacerías para evitarles el bochornoso espectáculo de las conejas que se dedican a la prostitución" ( Caza 92). Lo erótico es abordado para explorar el espacio de lo siniestro donde el deseo y la muerte se mezclan: "Y si ella apretaba un poco demasiado con sus muslos, al conejo se le nublaban los ojos y moría dulcemente, graciosamente, o aun con indiferencia" (16). Caza de conejos se construye como una permanente puesta en cuestionamiento del sentido común, volviendo inestables las premisas de las que el lector puede sujetarse al sumergirse en la narración. Una imagen repetida en la novela son los carteles con la leyenda "PROHIBIDO CAZAR CONEJOS". La primera vez que la ven, los cazadores violan esa reglamentación: "Preparamos una fogata con todos los carteles de madera que decían 'PROHIBIDO CAZAR CONEJOS' y asamos los conejos a las brasas" (19). En tanto que, cuando en otro momento aparece el cartel, su reacción es de resignación: "Nos dimos media vuelta y regresamos, muy tristes, al castillo" (51). La novela rompe con el horizonte de expectativas del lector que el propio texto ha creado. No solo cuestiona el sentido común sino los propios sentidos que la misma narración plantea. 
En "El sótano" también es evidente el parentesco con Lewis Carroll. En este cuento, no obstante, predomina un imaginario infantil sin la intervención de lo erótico. El texto incluso está editado en forma independiente, en una colección de literatura para niños de Alfaguara con ilustraciones de Horacio Guerrero, además de formar parte del libro $L a$ máquina de pensar en Gladys. Se trata de una apropiación en la que construye su propia versión de este tipo de relatos, siempre limítrofe, cercana a la parodia, en el que expone el artificio de los protocolos escriturarios de la denominada, por motivos comerciales, literatura infantil.

El texto narra la curiosidad de un niño, Carlitos, por saber qué cosas hay en el sótano de su casa. La puerta que conduce al mismo está celosamente cerrada por sus padres con un candado. La falta de razones o explicaciones justificadas de los adultos sobre el porqué de la prohibición no hacen más que aumentar las expectativas y los deseos del chico: "Porque allí — respondió el padre — hay algo que nadie debe conocer" (La máquina 35); "No- respondió ella-. Jamás podrás bajar al sótano; nunca encontrarás la llave y nunca, nunca, nunca podrás bajar" (36). Por la forma en que están formuladas, las negativas de los padres son casi una invitación a la exploración y a la trasgresión de la norma. El relato se organiza a partir del despliegue de este deseo. Carlitos recorre la casa, investiga, pregunta a sus abuelos y a una serie de personajes maravillosos, al estilo de los de la serie de Alicia de Carroll, quienes mediante desafíos y acertijos lo conducen y desvían en su viaje. En el afuera, en el jardín, encuentra al insecto Tito quien le dice que desobedezca el cartel con letras mayúsculas que reza "PROHIBIDO PISAR EL CÉSPED", como estrategia para ser llevado por alguno de los inspectores frente al Jefe de los Jardineros. Según Tito, este conoce quién tiene la llave de la puerta que da al sótano. El Jefe es muy mentiroso, pero de imaginación limitada, por lo que a la tercera pregunta no tiene más remedio que decir la verdad. De esa manera, Carlitos logra saber que es el Tragafierros quien tiene la llave. En el camino, mientras huye de los inspectores enviados por el Jefe para castigarlo por haber pisado el césped, se encuentra con un hombrecillo que vive encerrado en una celda imaginaria. Este había sido condenado, pero la prisión se derrumbó. Por conveniencia — para él porque los esbirros le siguen trayendo comida y para los esbirros porque son haraganes y no quieren construir otra celda - todos teatralizan como si el calabozo siguiera en pie. Se trata de una descripción del funcionamiento de la ideología, que no es un mero engaño o una falsa consciencia: "Por lo tanto, aunque hace ya muchos, muchísimos años que no existe la celda, sigue existiendo para ellos y para mí; y tanto nos interesa que exista, que la vemos, y la tocamos" (56). En su polémica con la generación crítica, Levrero propone superar las prisiones imaginarias que limitan sus concepciones de realidad y, por ende, de su estética.

"El sótano" concluye cuando Carlitos logra apropiarse de la llave que tiene el Tragafierros. En ese momento ya es, Carlos, un adulto con bigote y canas. La casa está vacía y no están sus padres. El relato termina cuando comienza a bajar la escalera. El sentido iniciático del texto expone una de las matrices compositivas de la literatura levreriana: la infancia como "espacio libre" donde la curiosidad y el deseo impulsan el viaje imaginativo sin las restricciones institucionales y sociales que limitan la vida adulta: " [...] los niños no tienen propiedades, la propiedad de las cosas es asunto de las personas mayores; es en realidad, el 
principal asunto de las personas mayores, tan importante que la Historia y las guerras se tejen en su torno" (La máquina 32).

En 2018, se publica también Cuentos cansados con ilustraciones de Diego Bianki dentro de un catálogo pensado para la infancia. El relato forma parte, originalmente, del libro El portero y el otro y es un homenaje lúdico para su hijo Nicolás Varlotta. El texto se compone de los diálogos entre un niño, Nicolás, y su padre, "YO", en los que todas las noches el hijo pide que le cuenten un cuento. El padre alega que está agotado por lo que solo le puede contar un cuento cansado, es decir, un relato que recurre al imaginario y los protocolos de este tipo de narraciones, pero que está entrecortado por signos de cansancio como los bostezos, los ronquidos o el silencio repentino al quedarse dormido, lo que obliga, a veces, a la intervención del niño para despertarlo. En esta versión "cansada" de Sherezade, Levrero desplaza el contar para salvar la vida a un narrar para rescatarla de la alienación agotadora del trabajo en la vida adulta. La escritura en su obra se configura como una máquina para disparar la curiosidad de un niño interior a través de la irrupción del absurdo, la búsqueda infinita y el juego con la imaginación desbordante. El uruguayo considera a la literatura un "espacio libre" que asocia a la infancia y construye su figura de autor como un raro que rehúye a la institucionalización y al trabajo como organizador enajenante de la vida social. En este sentido, el uso del humor se convierte en Levrero en un vehículo hacia lo trascendente, en la llave, negada por la autoridad de lo socialmente aceptado, que impulsa el viaje, el despliegue del deseo.

\section{Consideraciones finales. Un libertinaje imaginativo para asediar lo real}

La presencia del humor es un recurso distintivo en la literatura de Levrero y existen diferentes aportes críticos que lo destacan. Sin embargo, a esta decisión de darle un marcado rasgo humorístico a su obra, el uruguayo no la toma sin ciertas vacilaciones: la primera publicación de Nick Carter se divierte mientras el lector es asesinado y yo agonizo no aparece con la firma de Mario Levrero debido a los temores de que un texto excesivamente paródico sea rechazado dentro de un campo literario, caracterizado por la "seriedad" de la llamada generación crítica. Esta tensión no ha sido abordada y se trata de una clave para entender el proyecto escriturario levreriano, en general, y el lugar del humor en su poética, en particular. La disputa con la generación precedente, quien lo tilda de practicar un libertinaje imaginativo (Rama 244), adquiere un carácter programático sobre los alcances de la literatura, el realismo, la imaginación y el humor. Frente a la acusación de anarquía y ausencia de un plan, Levrero responde señalando que la crítica ejerce una función policial para impedir que la locura inmanente en los textos se expanda en la sociedad. Frente a la literatura comprometida y con mayúscula, rescata los géneros marginales como el folletín policial, el humor y el absurdo como máxima expresión de la belleza.

Levrero se considera un autor realista que trabaja con materiales de la interioridad y pretende el reconocimiento de la imaginación como un elemento constitutivo de esta estética. En la "Irrupción 64" da cuenta de una polémica con un "amigo crítico", del que no revela el nombre, sobre los límites del realismo. El escritor rioplatense vincula a dicho amigo con 
Rama, por lo que el texto se organiza en la forma de una discusión con este y la crítica que, concibe que: "La realidad es una realidad social que no tiene en cuenta la física contemporánea ni se interesa por el comportamiento paradojal de la luz, y de la materia en general, ni muchas otras existentes" (Irrupciones 228). En el fragmento, Levrero - el raro, el esotérico, el libertino - utiliza la autoridad de la ciencia para exponer los prejuicios de su oponente. El ataque a las concepciones sociológicas de la literatura y su noción restringida de lo real es una forma de reclamo por la incorporación de su propia poética. Cuando el uruguayo pide ir más allá de la mímesis y que se incluya la imaginación dentro de la realidad, está buscando legitimar su obra: "Lo que yo señalo es justamente el error de contraponer realidad e imaginación. La imaginación forma parte de la realidad, si entendemos la realidad como lo existente" (Irrupciones 227).

Levrero impugna los límites en los que la generación crítica procura encorsetar a la literatura. La polémica, retomada en intervenciones públicas y en esa arte poética que es su autoentrevista imaginaria, implica un ajuste de cuentas contra "los profesores" que pretenden reducir la literatura al ejercicio asépticamente intelectual. El uruguayo entiende la escritura como una apuesta vital - "esto no es una novela carajo, me estoy jugando la vida" (El portero 134)-, un dispositivo terapéutico y una forma de vida. En el marco de esta toma de posición adquiere un mayor espesor el uso del humor en la obra de Levrero y el resto de sus heterónimos.

Su reivindicación del libertinaje imaginativo del que lo acusa Rama adquiere ribetes programáticos: destacar ese plus como constitutivo de la literatura y el humor como rasgo distintivo de ese exceso. La escritura para Levrero es un dispositivo o mancia que posibilita el contacto con una realidad más amplia, el Inconsciente o el Espíritu. Al trabajar con materiales oníricos, el absurdo, los montajes insólitos, la ruptura del orden lógico y el arte combinatorio, el uruguayo manifiesta esa búsqueda que, de manera recursiva, tiene lugar en la literatura y que es la literatura misma. Se trata de un proyecto (im)posible en el que el deseo y la realización se entremezclan.

La literatura se convierte así en un "espacio libre" asociado al momento idílico de la infancia y en contraste a la vida de los adultos, enajenada por las obligaciones sociales. En la cosmovisión del uruguayo, el primer alienado es su yo cotidiano, Jorge Varlotta, ese heterónimo que funciona como condición de posibilidad para la existencia del escritor, Mario Levrero. Como explicita en "Diario de un canalla", Varlotta sobrevive como puede a sus rutinas laborales y faltas de todo tipo para que se produzca ese espacio libre de la escritura donde habita Levrero.

En uno de los textos de la serie "Literatura, literatos, libros", de Irrupciones, el uruguayo remarca la diferencia entre el escritor aficionado y el profesional. Señala que, se trata de autores que ocupan espacios creativos antagónicos, el primero inspirado por la musa o el Inconsciente, el segundo estimulado por el dinero. Él se considera "un ejemplo nítido de aficionado" (354). Desde este posicionamiento ético y estético, Levrero concibe la literatura como un dispositivo terapéutico que habilita el (auto)conocimiento. Un proyecto (im)posible, la ilusión del Uno, que se produce mediante la desarticulación de la normativa social y de 
la lengua. El humor, en especial el absurdo, es una forma que asume esa fisura en el sentido que posibilita la emergencia del Espíritu/Inconsciente. La escritura es un discurrir en la búsqueda, destinada de antemano al fracaso, de una experiencia luminosa donde el costo es muy alto y que se sostiene en un acto de fe. Al igual que los niños, que siempre juegan en serio, el rioplatense afirma que se está jugando la vida en su fe en la literatura, aunque a veces vacile y se permita dudar, como plantea, con humor, en una de sus Irrupciones:

Dios me va a ayudar, Dios no va a permitir que me quede sin techo ni que pase hambre. Perdón, Dios mío, por haber perdido la fe, en un rapto de locura. Ya no intentaré rehuir de mi deber. Ya no seguiré buscando empleo. Ya no pensaré en dejar de escribir. (115)

\section{Referencias}

Bajtín, Mijaíl. La cultura popular en la Edad Media y en el Renacimiento. El contexto de François Rabelais. Trad. Julio Forcat y César Conroy. Madrid, Alianza Editorial, 2003.

Benjamin, Walter. "El surrealismo. La última instantánea de la inteligencia europea". Imaginación y sociedad. Iluminaciones I. Trad. Jesús Aguirre. Madrid, Taurus, 1999, pp. 41-62.

Cosse, Rómulo. "Rasgos estructurales fuertes en el relato breve de Levrero". Nuevo Texto Crítico 8, 16/17, (1996): 35-43. Impreso.

Fuentes, Pablo. "Levrero: el relato asimétrico". La máquina de pensar en Mario. Ensayos sobre Levrero. Comp. por Ezequiel de Rosso, Buenos Aires, Eterna Cadencia, 2013, pp. 27-38. Impreso.

Gandolfo, Elvio (comp.). Un silencio menos. Conversaciones con Mario Levrero. Buenos Aires, Mansalva, 2013.

García, Germán. Macedonio Fernández. La escritura en objeto. Buenos Aires, Adriana Hidalgo Editora, 2000.

Kohan, Martín. 1917. Buenos Aires, Ediciones Godot, 2017. Impreso.

Levrero, Mario. El portero y el otro. Montevideo, Arca Editorial, 1992. Impreso.

La máquina de pensar en Gladys. Montevideo, Arca Editorial, 1998. Impreso. 
Caza de conejos. Buenos Aires, Libros del Zorro Rojo, 2012. Impreso.

Irrupciones. Montevideo, Criatura Editora, 2013. Impreso.

“El crucificado". Espacios Libres. Montevideo, Irrupciones Editorial, 2014, pp. 4853.

Martínez, Luciana. "Mario Levrero, la ciencia y la literatura”. La máquina de pensar en Mario. Ensayos sobre Levrero. Comp. por Ezequiel de Rosso, Buenos Aires, Eterna Cadencia, 2013, pp. 165-190. Impreso.

Montoya Juárez, Jesús. Mario Levrero para armar. Jorge Varlotta y el libertinaje imaginativo. Montevideo, Trilce, 2013.

Núñez, Matías. "La biblioteca errante. Escenas de lectura en La novela luminosa de Mario Levrero". Revista de la Biblioteca Nacional 11-12 (2016): 257-273. Web. 26 feb. 2021.

Rama, Ángel. La generación crítica (1939-1969). Montevideo, Arca Editorial, 1972.

Rivadeneira, Blas. "La escritura como dispositivo terapéutico y forma de vida. Poética y lugar de autor en el escritor uruguayo Mario Levrero". Orbis Tertius 25, 32 (2020): e164. Web. 15 abr. 2021. https://doi.org/10.24215/18517811e164

Rocca, Pablo. "Formas del espionaje. Mario Levrero responde un cuestionario". La máquina de pensar en Mario. Ensayos sobre Levrero. Comp. por Ezequiel de Rosso, Buenos Aires, Eterna Cadencia, 2013, pp. 79-111. Impreso.

Sanchiz, Ramiro. "Mario Levrero y el humor: chistes, lecturas erróneas y disonancia cognitiva". Cuaderno de historia 17 (2016): 29-36. Web. 4 mar. 2021.

Várnagy, Tomás. "Proletarios de todos los países... iperdonadnos!" o sobre el humor politico clandestino en los regímenes de tipo soviético y el papel deslegitimador del chiste en Europa Central y Oriental (1917-1991). Buenos Aires, Eudeba, 2016.

Verani, Hugo. "Mario Levrero: aperturas sobre el extrañamiento". Nuevo Texto Crítico 8, 16/17 (1996): 45-58. Impreso. 